REVISTA X, Curitiba, volume 12, n.2,p.217-230,2017

\title{
CONSIDERAÇÕES DA ABORDAGEM FUNCIONALISTA EM UM TEXTO EM PORTUGUÊS DE UM PROFESSOR JURUNA ${ }^{1}$
}

\section{Considerations of Functionalist Approach in a text in Portuguese of a Juruna teacher}

Lígia MOSCARDINI $^{2}$

RESUMO: Este artigo apresenta uma abordagem funcionalista nas análises de um texto em português como segunda língua, coletado em oficina de leitura e escrita na escola Kamadu, da etnia juruna, localizada em Mato Grosso-MT. A proposta de texto foi trazida por um professor indígena, que pretendia elaborar um roteiro de vídeo a ser filmado. Por tal motivo, foram feitas orientações para colaborar, ainda que por um curto período, com a alta demanda do ensino de português na escola Kamadu, com enfoque no ensino de leitura e produção de texto, visando o uso e reflexão linguística e, com isso, a preservação cultural. Nesse sentido, a linguística funcional pode contribuir para a eficácia dessa proposta por priorizar, dentre outros aspectos, o uso linguístico e contexto interacional. Para isso, foram utilizadas bibliografias sobre os juruna e escola Kamadu e sobre vertentes do funcionalismo adequadas para a análise de texto, com o objetivo de se analisar a finalidade e expressividade das escolhas linguísticas feitas por um falante de português como segunda língua.

Palavras-chave: Abordagem funcionalista; Professor indígena; Produção de texto.

ABSTRACT: This article presents the usage for the functionalist approach in the analysis of a text in Portuguese as a second language, collected in a reading and writing workshop at the juruna school Kamadu, located in Mato Grosso-MT. The proposed text was brought by an Indian professor who wanted to develop video script to be filmed. Therefore, the guidelines have been elaborated in order to collaborate, even for a short period of time, with the high demand of the Portuguese education in the Kamadu school, focusing on the teaching of reading and text production, aiming at the linguistic elements as well as their cultural preservation. In this sense, the functional linguistics perspective may contribute to the effectiveness of this proposal for prioritizing, among other aspects, the linguistic use and theinteractional context. In order to do so, it was used the juruna and Kamadu school bibliographies and the most suitable aspects of the functionalism to carry out the text analysis, as well as to analyse the purpose and expressiveness of the language choices made by a speaker of Portuguese as a second language.

Keywords: Functionalist approach; Indigenous teacher; Text production

\footnotetext{
${ }^{1}$ Juruna Teacher is a teacher of an Indigenous Ethnicity

${ }^{2}$ Doutoranda em Linguistica e Lingua Portuguesa (UNESP). $\underline{\text { mosca2120@gmail.com }}$
} 
O povo juruna, cuja auto-denominação é yudjá, que significa “dono do rio”, vive em sete aldeias, próximas à BR-80, na Terra Indígena Xingu (Tubatuba, Matxiri, Pequizal, Paqsamba, Pakayá, Pakajá, Mupadá) e em dois postos indígenas na mesma região (Posto Diauarum e Posto Piaraçu). A população é de 400 pessoas, aproximadamente, todos falantes da língua indígena (FARGETTI, 2010).

A aldeia possui uma escola cujo nome é "Escola Estadual Indígena Central de Educação Básica Kamadu”. Segundo Fargetti (2010), esta escola tem início entre 1994 e 1995 , com construção em alvenaria concluída apenas em 2006, e apoio do ISA para regime interno e ainda hoje para oficinas. (op.cit. p.60-61).

Conforme o Projeto Político Pedagógico da escola, somente com a criação da Associação Yarikayu, que começou registrando músicas das festas tradicionais, é que convenceram a comunidade juruna de que a escola também poderia ter tal função de resgate cultural, principalmente quando, logo depois, a escola ajudou nas pesquisas históricas e nas transcrições das letras de tais músicas (PPP, p.14). Por esse motivo, os professores juruna integraram o curso de formação em magistério para professores indígenas no Parque Indígena do Xingu, com acompanhamento do Instituto Socioambiental (ISA). (PPP, p.13).

Ainda segundo Fargetti (2010), em Tubatuba nunca houve professor não-índio, apenas pesquisadores e assessores para o ensino bilíngue. Os professores juruna, em sua maioria, são formados por curso de nível superior na UNEMAT, com diploma de professor na língua, arte e literatura juruna, com cargo do estado de Mato Grosso. Têm ensino de língua indígena, avaliações e diários de classe e, pelos resultados positivos, poucos estudam na cidade. (op.cit. p.60-61). Além do mais, apontamos em Moscardini (2011), que os juruna explicam que o nome Kamadu, significa "bonita" em português, porque, segundo eles, a escola deve ser atrativa para crianças, jovens e adultos para que aprendam e ensinem de forma coletiva. Instituíram a escola para aprenderem a escrita do não-índio e ao mesmo tempo, preservarem sua cultura. (MOSCARDINI, 2011).

Nesse sentido, a escrita do não-índio, que é o português como segunda língua para eles, é um veículo caro à comunidade, pois está atrelada tanto com o objetivo de se preservar a 
cultura quanto o de interação com o não-índios, ao elaborarem cartas, ofícios, relatórios, trabalhos para cursos de formação, dentre outros. Dessa forma, o português, anteriormente tomado como língua do colonizador, agora se torna um instrumento de resistência e luta dos indígenas e, com isso, um aliado. Tal importância, juntamente com o interesse em aprender o português como Segunda Língua, está transcrita também em passagens do PPP:

Espera que a escola ensine coisas boas (que ajudem na nossa realidade), o português e a tradição pra preparar para o futuro (PPP, 2008, p.18, grifo nosso)

Para a formação de um bom escritor é necessário um leitor competente”. (Idem, p. 28)

A escola deve ensinar a escrita e a fala do não-índio para se comunicar com falantes de outras línguas, também deve ensinar a escrita da nossa língua e fortalecer nossa cultura. (PPP, 2008, p.21)

Habilidades na área de linguagem e comunicação

Dominar a leitura e escrita da língua portuguesa e materna

Falar bem a língua, conjugando bem os verbos.

Ter facilidade para falar o português, conjugando bem os verbos

Conhecer as palavras da língua erudita

Fazer radiograma e ofício

Saber fazer projeto e relatório

Saber fazer documentos

(PPP, 2008, p. 27)

Apesar dessas demandas em Língua Portuguesa, conforme mencionamos em Moscardini (2015), foram notadas, em trabalhos de campo, algumas crenças na escola juruna em relação a ela, presentes em relatos de que os alunos "escrevem pouco" e "têm medo de escrever português errado". (sic). Tais depoimentos são lamentáveis, pois evidencia que os juruna não se sentem à vontade de se expressarem em segunda língua, como se houvesse o estigma de que precisam ter mais cuidado ao se expressarem em português do que ao se expressarem em juruna. Tanto que criaram até um "internetês juruna", enquanto creem que têm limitações quanto à segunda língua. Por outro lado, esta também é uma evidência que os professores e os alunos sabem quando seu texto em português não está adequado a uma dada situação e por isso solicitam meios de melhorá-lo. (MOSCARDINI, 2015).

Para atender a essa solicitação, há a demanda pela abordagem da língua portuguesa de um modo sociointeracional, para que a língua portuguesa se mostre uma aliada do povo juruna. Ora, conforme mencionado no PPP, os indígenas compreendem a importância da habilidade de "saber fazer documento" e, de fato, escrevem cartas, ofícios, projetos, trabalhos de universidades que frequentam e, por tais motivos, a aprendizagem de português significa, sobretudo, interação linguística. 
Nesse sentido, tomamos como reflexão a concepção de linguagem descrita pelo Funcionalismo, que pressupõe tal interação linguística. Pretende-se, com isso, analisar o modo como os elementos do gênero pretendido pelo professor juruna dão expressividade ao texto e de que forma atende a seus objetivos, que é redigir um texto ficcional e torná-lo apto a ser filmado. Tal processo de intervenção é, evidentemente calcado em uma competência comunicativa de interação, uma vez que exige um cuidado metodológico, de se considerar o contexto da escola Kamadu, o objetivo de filmar o texto e, ainda, a relação índio/não-índio.

\section{FORMALISMO E FUNCIONALISMO}

Para melhor compreensão da concepção funcionalista, faz-se necessário distinguí-la da concepção formalista. Nesses termos, de acordo com Martelotta \& Areas (2003) ${ }^{3}$, a publicação de Curso de Linguística Geral deixou um importante legado teórico, quando concebia a língua como um sistema. Este termo foi substituído posteriormente por estrutura e se consolidou dentre norte-americanos que fundaram a Escola de Copenhague. (MARTELOTTA \& AREAS, 2003). Os autores citam Hjelmslev, que propõe a língua como uma "unidade encerrada em si mesma, como uma estrutura sui generis", pensamentos que, afinal, sintetizam o formalismo. Neves $(1997)^{4}$, por sua vez, também explica que o formalismo foi definido por níveis linguísticos, como morfema, fonema, lexema e sintagma e que, dentro de tal concepção, a língua é um conjunto de orações e propõe a capacidade de produzi-las e interpretá-las com a concepção de que a língua tem como função expressar pensamentos. (NEVES, 1997)

Alguns anos após Saussure, temos o formalismo russo estudado por Jakobson. De acordo com Santee \& Temer (2011), Jakobson estabeleceu uma linguística formal e isenta do regime soviético. Depois, influenciado pela Teoria Informacional da Comunicação, verificou que muita atenção era dada ao código em detrimento do significado. (SANTEE \& TEMER,

\footnotetext{
${ }^{3}$ MARTELOTTA, M.E., ÁREAS, E. K. A visão funcionalista da linguagem no século XX. In: CUNHA, M.A.F, OLIVEIRA, M.R. MARTELOTTA, M.E. (orgs.) Linguística Funcional: teoria e prática. Rio de Janeiro, DP\&A, 2003.

${ }^{4}$ NEVES, M. H. M. A Gramática funcional. São Paulo, Martins Fontes. 1997.
} 
2011, p.74-78) e aprofundou essas concepções em seu artigo Linguística e Poética, no qual se lê:

O REMETENTE envia uma MENSAGEM ao DESTINATÁRIO. Para ser eficaz, a mensagem requer um CONTEXTO a que se refere (ou 'referente', em outra nomenclatura algo ambígua), apreensível pelo destinatário, e que seja verbal ou suscetível de verbalização; um CÓDIGO total ou parcialmente comum ao remetente e ao destinatário (ou, em palavras, ao codificador e ao decodificador da mensagem); e, finalmente, um CONTACTO, um canal físico e uma conexão psicológica entre o remetente e o destinatário, que os capacite a ambos a entrarem e permanecerem em comunicação. Todos estes fatores inalienavelmente envolvidos na comunicação verbal podem ser esquematizados como segue (JAKOBSON, 2008, p.74-78 apud SANTEE \& TEMER, 2011, p.79).

Com isso, Jakobson trouxe as funções da linguagem, que ia além da concepção de língua enquanto estrutura, pois explicava seus processos. Tal concepção contribuiu de maneira considerável com o que que se define hoje por Funcionalismo, pois, a partir desse ponto de vista, percebeu-se que a linguagem era um fenômeno mais complexo do que aquele voltado apenas para estruturas, uma vez que a linguagem é, também, pragmática, por ser um meio de comunicação e interação social. A partir de então, as estruturas linguísticas não se faziam suficientes para explicar o funcionamento linguístico. Em meio a isso, influências como a do psicólogo alemão Karl Bühler levaram linguistas do Círculo Linguístico de Praga a se dedicarem ao estudo da lógica interna do sistema da língua, produzindo o aspecto funcionalista. Em meio a isso, a Escola de Praga passou a adotar uma noção teleológica de função e, com isso, percebia que a língua deve ser compreendida como funcional, no sentido de que deve ser utilizada para determinado fim, para determinada finalidade. (MARTELOTTA \& AREAS, 2003).

Dessa forma, o funcionalismo concebe a língua como instrumento de interação social, propondo uma competência comunicativa. Sobre a gramática funcional, Neves (1997) a define a como "uma teoria de organização gramatical das línguas naturais que procuram integrar-se em uma teoria de interação social" (NEVES, 2007, p. 15) que tem como hipótese fundamental explicar as regularidades dentro da língua em aspectos recorrentes e circunstâncias de usos linguísticos. A partir de então, tem-se o "fluxo" do texto, gramática, que contém embasamento cognitivo e discurso, que inclui eventos comunicativos, composto inclusive a linguagem nãoverbal. Com Prideaux apud Neves (1987), diferenciou funcionalismo de estruturalismo, ao mencionar que a linguagem não é um fato isolado e, com isso, a gramática funcional considera 
o uso de expressões linguísticas na interação verbal, de modo a tornar pragmáticas as relações sintático-semânticas.

No entanto, deve-se evitar atribuir valores maniqueístas de que o funcionalismo seja "melhor" ou "mais avançado" que o formalismo, pois são vertentes que analisam o fenômeno linguístico, porém em perspectivas diferentes. De acordo com Pezatti (2006):

Além do mais, esse tipo de afirmação, ao enfatizar exageradamente a recusa às explicações formalistas, retirada corrente funcionalista o que lhe é mais caro: em primeiro lugar, a concepção de linguagem como um instrumento de comunicação e de interação social e, em segundo lugar, o estabelecimento de um objeto de estudos baseado no uso real, o que significa não admitir separações entre sistema e uso, tal como preconizam tanto o estruturalismo saussureano, com a distinção entre língua e fala, quanto a teoria gerativa, com a distinção entre competência e desempenho. (Pezatti, 2006, p.154)

Assim sendo, as duas vertentes podem ser complementares, já que não existe "forma ou uso", mas sim "forma e uso", justamente porque o uso linguístico está inserido em determinadas estruturas. O que não pode ocorrer é uma abordagem esparsa da estrutura da língua em sala de aula, como se ela fosse um mero conjunto de orações e elementos linguísticos. Infelizmente, isso ainda ocorre da pior forma em algumas escolas não-indígenas, em que o professor ensina apenas lições de gramática, e em séries iniciais, como se a língua fosse um fim em si mesma. Tal atitude, claro, é responsável por preconceitos que levam o aluno a "achar português difícil" e a afastá-los da leitura e da escrita.

Na escola, o estruturalismo traz relevâncias como permitir ao falante que conheça a sua própria língua, que tome consciência de sua língua, uma vez que já produz orações numa sequência que faz sentido, e, dessa forma, permite que o falante estabeleça uma relação entre língua e pensamento. A estrutura faz parte da língua, mas ela, em si, não ensina a falar e a escrever com precisão. Nesse sentido, o funcionalismo, tece, também, grandes contribuições ao ensino, algo confirmado por Neves (1997), a partir de suas propostas de pensar a língua como uso, como meio de interação, além de passar a analisar o modo como o falante faz isso. Lamentavelmente, o funcionalismo é pouco conhecido dos professores. Porém, o ponto positivo é o de que há projetos interessantes ocorrendo nas escolas com práticas voltadas para interação e uso linguísticos, o que causa um bom efeito na aprendizagem da língua. Por exemplo, uma professora de português criou um blog com alunos de oitavo ano para se comunicarem com 
alunos de Portugal, visando possibilidades de interação real e assimilação do que seja "variação linguística".

Na escola indígena Kamadu é nítida a demanda pela aprendizagem do português como segunda língua com objetivo de interação com não-índios. Conforme já mencionado, no Projeto Político Pedagógico da escola é observável o intuito de aprenderem a estrutura da língua portuguesa em passagens como "Ter facilidade para falar o português, conjugando bem os verbos" ou "Conhecer as palavras da língua erudita

(PPP, 2008, p. 27)”, mas que também espera abordagens mais caras ao funcionalismo, observável em passagens como "Espera que a escola ensine coisas boas (que ajudem na nossa realidade), o português e a tradição pra preparar para o futuro (PPP, 2008, p.18, grifo nosso)" e em "A escola deve ensinar a escrita e a fala do não-índio para se comunicar com falantes de outras línguas, também deve ensinar a escrita da nossa língua e fortalecer nossa cultura. (PPP, 2008, p.21)". Atentando-se a isso priorizaremos, neste estudo, um enfoque maior sobre como a abordagem funcionalista em um texto juruna pode contribuir para um melhor ensino do português como segunda língua na escola da aldeia.

\section{ANÁLISE DE UM TEXTO ESCOLAR JURUNA DE ACORDO COM O FUNCIONALISMO}

Percebemos que o funcionalismo é uma linha teórica mais centrada no uso linguístico e no que a situação comunicativa determina. Para tanto, se utiliza de algumas escolhas linguísticas. Segundo Modesto (2006) “As escolhas se situam no nível paradigmático, enquanto no nível sintagmático estão as cadeias de relações. Todo esse processo produz um texto, que pode ser caracterizado como uma representação do sistema social e linguístico." (MODESTO, 2006, p.2-3) e que, conforme Cunha, Costa Cezario (2003) "a estrutura se fará pela situação comunicativa e contexto de uso" (op.cit. p.29). Em meio a isso, o britânico Halliday concebeu a linguística sistêmico-funcional, na qual via a língua como um conjunto de sistemas utilizado pelos falantes para produzir significados no contexto social em que vivem. Esse conjunto de sistemas no qual o ser humano se expressa e se posiciona precisa se organizar textualmente. Nesse sentido, a Linguística Sistêmica permite que analisemos o modo como os textos conseguem ou não expressar esses significados de acordo com escolhas linguísticas do falante. Dessa forma, a linguística Sistêmico-Funcional traz contribuições para a análise do texto. Halliday apud Santos (2014):

${ }^{5}$ CUNHA, M. A. F., COSTA, M, A, CEZARIO, M. M. Pressupostos teóricos fundamentais. In: CUNHA, M.A.F, OLIVEIRA, M.R. MARTELOTTA, M.E. (orgs.) Linguística Funcional: teoria e prática. Rio de Janeiro, DP\&A, 2003. 
Nós podemos definir texto, talvez da forma mais simples, dizendo que ele é a língua que é funcional. Por funcional, queremos dizer simplesmente que a língua está sendo usada em algum contexto, em oposição a palavras ou sentenças isoladas que poderiam ser colocadas em um quadro (...). Assim, qualquer instância de língua viva inserida em um contexto de situação, podemos denominar texto. Ele pode ser escrito ou falado, ou de fato em qualquer outro meio de expressão que nos leva a refletir. (HALLIDAY, 1989, p. 10 apud SANTOS, 2014, p.169)

Pensando nisso, investiga-se de que forma essa visão pode estar atrelada no modo como professores e alunos da escola Kamadu produzem um texto em português. Para isso, tomamos como base um texto narrativo, com a finalidade de ser filmado. De acordo com tal objetivo aponta-se, antes de tudo, o quanto eles interagem bem com aparatos tecnológicos, o que fica evidente em suas habilidades para com eles e no interesse por oficinas sobre fotografia e filmagem, já ministradas na escola. O apreço pela tecnologia é perceptível inclusive entre as mulheres da comunidade, que outrora realizava apenas trabalhos domésticos, o que é um ponto curioso. Com isso, aplicam a tecnologia na preservação cultural, pois já filmaram seus eventos e conhecimentos de pessoas idosas da comunidade juruna.

Apesar de essa ser uma atitude inegavelmente importante para a comunidade, se percebeu, em oficina de produção de texto ministrada em Abril de 2012, um outro tipo de interesse para além de registrar narrativas mitológicas conhecidas apenas dos idosos, porque também buscam um outro tipo de narrativa: histórias ficcionais, produzidas por eles mesmos, para posterior filmagem. É um aspecto muito importante e que afinal vai além do senso comum sobre o uso do português por indígenas. Outro fator relevante é o de que tal produção ficcional foi iniciativa do próprio indígena, algo bem diferente de quando se elaboram coletâneas com propostas de produção de texto para que escrevam algo a partir dela, embora estas também possuam sua relevância na aprendizagem de gêneros escritos.

A partir disso, entrou-se em contato com a teoria funcionalista, que instiga a questionamentos: Qual será o conceito desse professor indígena sobre o tipo textual a ser filmado? É possível que ele tenha boas razões para determinada escolha estrutural, lexical, de personagens, de situações, dentre outros? Como ele interage com o Outro através do texto? De que forma os termos por ele utilizados podem estar atrelados ao domínio da segunda língua e ao uso linguístico, tão caro à Linguística Funcional? Com isso, procura-se tecer breves considerações acerca do texto apresentados confluências com a Linguística Funcional.

Assim sendo, vejamos, na íntegra, um texto-base produzido por um juruna para posterior filmagem: 
Um pequeno povo chamado de Axiha que habitava a floresta, o cacique do povo que tinha uma filha tão bela com cabelo preto e longo pelas costa. A moça ficou por muito tempo na reclusão.

Até que chegou um momento que o pai da moça resolveu tirar a sua filha de reclusão. $O$ cacique do povo reuniu seu pequeno grupo e decidiram realizar a festa para a moça. Então houve a festa. Mas Durante a festa a aldeia foi atacado pelos inimigos chamado Arupai. O cacique foi morto a borduna pelo o chefe do inimigo e não salvou sua filha. Durante o ataque raptaram 2 moças, e junto delas a filha do cacique, e foram levadas pelos inimigos. Mas graças a um rapazforte e corajoso, as moças foram resgatadas.

(Texto do professor juruna)

Esse texto, embora muito curto, possui bastantes elementos para ser analisados, desde elementos de coesão e coerência até elementos de domínio linguístico e extralinguísticos. Isso é bem relevante no que diz respeito à Educação Escolar Indígena pois, conforme foi dito, os índios "têm medo de escrever português errado". Nesse texto, alguns elementos apontam para um pouco de conhecimento em português e ajudam a analisar o porquê de cada escolha linguística desse indígena para produzir significados e o modo como cada advérbio e referência têm um motivo para estar lá e atenderem a seus objetivos.

Assim, nenhuma escolha é aleatória em sua narrativa e visa produzir significados, argumentos narrativos e elementos de conflito e desfecho em sua narrativa. Vejamos, portanto, algumas considerações sobre os elementos presentes nesta pequena narrativa.

\section{ANÁLISE DA COESÃO:}

\section{Referências:}

O primeiro ponto perceptível neste texto é o fato de o falante enumerar os elementos mais importantes da narrativa, e de uma forma mais direta, tais como "como " Um pequeno povo que habitava a floresta", "uma filha tão bela que estava de reclusão por muitos anos". 
Também pode ser visto algo da coesão referencial, como na sentença "Durante o ataque raptaram 2 moças, e junto delas a filha do cacique", em que o autor não repete personagens, mas faz referência a elas.

\section{Substituição:}

Outro ponto que se observa é uma substituição mais explícita para não se repetir termos. Isso está presente em sentenças como "o cacique do povo que tinha uma filha tão bela com cabelo preto e longo pelas costa. A moça ficou por muito tempo na reclusão" ou então "pequeno povo...pequeno grupo".

\section{Advérbios:}

Os advérbios também apresentam um papel importante no texto do indígena. Suas escolhas adverbiais fornecem maior expressividade e caracterização na narrativa e em seus acontecimentos. Isso é observável em "Um pequeno povo chamado de Axiha". Na oração ""uma filha tão bela com cabelo preto e longo pelas costas" o professor juruna conseguiu dar enfoque na beleza da protagonista. A expressão "A moça ficou por muito tempo na reclusão" também denota uma ênfase no cumprimento de ritual realizado pela moça e que, a partir de então, estava apta a outra etapa de sua vida. Na sentença "o pai da moça resolveu tirar a sua filha de reclusão", seu autor dá início a essa nova etapa e marca um conflito narrativo a partir da festa pela conjunção adversativa "mas" e o advérbio "durante", que é quando surge o ataque da outra aldeia.

\section{ANÁLISE DA COERÊNCIA}

\section{Domínio linguístico:}

Muito embora ainda falte elementos que o deixa mais claro, esse texto faz sentido para falantes do português como língua materna, apresenta pontuação e paragrafação adequada, além de ter começo, meio e fim. Tais elementos nem sempre se observam em textos dos professores e alunos juruna. Além disso, o texto também possui alguns argumentos narrativos que o compõe. Nesses argumentos, percebe-se que "decidiram realizar a festa para a moça", "Durante a festa a aldeia foi atacado pelos inimigos e o cacique foi morto", "foram raptadas 2 moças", Mas graças a um rapaz forte e corajoso, as moças foram resgatadas". A linguagem mais direta é frequente 
nas vezes em que os juruna lidam com o português, que é a segunda língua da comunidade. Também é importante verificar que a ênfase do texto do indígena está no essencial, e que é um texto sem diálogo, talvez transmitindo a visão deles sobre cinema, ou mesmo falta uma maior consciência quanto à gêneros em português.

\section{Domínio pragmático:}

A pragmática diz respeito à situação em que a interação está situada. Assim sendo, observa-se que era possível a reelaboração da estrutura do gênero roteiro, como as ações não verbais entre parênteses, quais as músicas escolhidas, o que vai ser ensaiado, dentre outros fatores típicos do gênero. Porém, tal versão já se apresenta interessante para uma filmagem curta, e assim fizeram. Além do mais, o indígena em questão faz algumas escolhas adequadas, em relação ao gênero narrativo, que implica o tempo verbal passado e a tão comum terceira pessoa do singular.

Outra escolha relevante corresponde tanto à finalidade de se elaborar um roteiro quanto ao modo como o professor juruna expressa o sistema social da aldeia, uma vez que fica claro, no texto, que o receptor do pequeno filme também será indígena, pois há elementos que o autor do texto não se preocupa em explicar, tais como "reclusão". Porque, se o filme fosse direcionada a um não-índio, ele teria de dizer o que é essa reclusão, como ela se dá nas culturas indígenas e por que se faz uma festa para sair dela. Portanto, considera-se que esta é outra das escolhas do falante, relacionada ao modo como ele considera adequado para narrar uma história e se ter um conflito e o autor da narrativa considerou elementos como "para que" e "para quem" se está escrevendo, o que cumpre a proposta tanto do funcionalismo, sobre o texto ter uma dada finalidade, quanto a proposta de Geraldi (2006), de que um bom texto precisa ser autêntico.

\section{Domínio extralinguístico:}

Tal domínio diz respeito ao conhecimento de mundo. Assim sendo, outro ponto primordial no que diz respeito a escolhas linguísticas para uma finalidade é o de que, ao fazer o texto, o indígena relata que não fez muitas descrições, já que pretende filmar algumas cenas que vão compor o texto Houve relatos do tipo "não preciso descrever isso, pois irá aparecer na filmagem". Em outras palavras, organiza seu texto de modo a não ter um fim em si mesmo, mas apenas servir de referência a um objeto a ser filmado. Tal constatação feita por ele é bastante 
correta, uma vez que o recurso descritivo era utilizado por romancistas exatamente em épocas em que não havia televisão nem a globalização que se tem hoje, de tal forma que era preciso descrever com detalhes elementos como o cavalo ou os vestidos dos personagens da narrativa. Em tudo isso, apreende-se que o professor indígena percebeu, de alguma forma, que o texto deve ser um roteiro, e não um conto, por exemplo, surpreendendo pela consciência de gênero.

Outro assunto a se destacar é o de que, ainda que este seja um filme direcionado a outros indígenas, também há elementos de narrativa europeia, como a moça, que afinal se assemelha a uma princesa de conto de fadas e um príncipe, o "rapaz forte e corajoso" que veio salvá-la do perigo. Tais elementos, provavelmente, estão relacionados ao conceito que o autor tem de um texto narrativo, de que o texto "deve ser assim para estar correto". E também é possível que esteja presumindo que estes são conhecimentos que o interlocutor também tenha.

\section{CONSIDERAÇÕES FINAIS}

Para que a língua portuguesa seja uma aliada de povos indígenas, seu ensino deve partir de boas abordagens. Conforme seu próprio Projeto político Pedagógico, os juruna esperam aprender sobre a estrutura da língua, e isso é relevante no que diz respeito a uma maior compreensão da língua portuguesa. Contudo, a abordagem formal não é a única possível e não é suficiente para situações de uso linguístico.

Nesse sentido, é imprescindível que se apresente, na escola da aldeia, uma abordagem funcional da língua, para que compreendam, também, o quanto a língua portuguesa está atrelada em suas situações de uso e, dessa forma, não pode ser desvinculada de práticas sociais. E é pelo uso linguístico voltado às práticas sociais, tão caro ao funcionalismo, que aprimorar habilidades em português como segunda língua se faz tão relevante a comunidades indígenas, pela frequência com que etnias como a juruna precisam lidar com a sociedade letrada. Ora, os indígenas escrevem cartas, ofícios, projetos, trabalhos de universidades que frequentam e, por tais motivos, a aprendizagem de português não pode, equivocadamente, ser reduzida à "aculturação". Pelo contrário, o estudo do português possui a mesma relevância de se preservar sua língua materna os falantes nativos, pois significa, sobretudo, interação linguística para também dessa forma manterem seus valores culturais. 
No caso específico dos juruna, essa é uma visão mais equivocada ainda, uma vez que já possuem uma política de preservação da língua materna à sua maneira e dentro da própria aldeia, em que não se pode falar em português no cotidiano entre os membros da comunidade. Além disso, as crianças aprendem, na escola, primeiro a língua materna para apenas posteriormente aprenderem a língua portuguesa. Assim sendo, eles próprios estabelecem, com autonomia e sem mediações de não-índios, os limites entre a língua portuguesa enquanto "perda" cultural ou enquanto aliada da comunidade.

No texto analisado, pôde-se observar o quanto a escolha de elementos linguísticos não foi aleatória para a finalidade do texto e do tipo de interação pretendido pelo juruna. Também foi observável o grau de domínio na segunda língua de acordo com o modo como a coesão e a coerência foram realizadas, e no modo como as operações linguísticas colaboraram para a produção do texto, bem como suas implicações pragmáticas e extralinguísticas. Enfatiza-se, ainda, que é um ponto alto o fato de se despontar um fazer artístico encontrado nessa narrativa, pois revela uma boa expressividade em português e, sem que isso interfira na língua materna, permite ver que eles percebem a importância da distinção de tipos textuais dentro de uma narrativa e, mais do que isso, nos permite verificar indícios de autenticidade indígena em um texto em português, a partir das escolhas linguísticas concebidas para determinada finalidade, algo que foi uma contribuição bem relevante da abordagem funcionalista.

\section{REFERÊNCIAS}

CUNHA, M. A. F., COSTA, M, A, CEZARIO, M. M. Pressupostos teóricos fundamentais. In: CUNHA, M.A.F, OLIVEIRA, M.R. MARTELOTTA, M.E. (orgs.) Linguística Funcional: teoria e prática. Rio de Janeiro, DP\&A, 2003.

FARGETTI, C.M. Para um Inventário da Língua Juruna (Relatório). Projeto Convênio IPHAN-ABRALIN. Araraquara: UNESP. 2010.

MARTELOTTA, M.E., ÁREAS, E. K. A visão funcionalista da linguagem no século XX. In: CUNHA, M.A.F, OLIVEIRA, M.R. MARTELOTTA, M.E. (orgs.) Linguística Funcional: teoria e prática. Rio de Janeiro, DP\&A, 2003.

MODESTO, A. T.T. Abordagens funcionalistas. Revista Letra Magna. Ano 03, n.4 - $1^{\circ}$ Semestre de 2006. São Paulo - SP. Disponível em: <http://www.letramagna.com/Abordagens.pdf $>$

MOSCARDINI, L. E. Seção II: confluências teóricas e metodológicas. In: Procedimentos Linguísticos na prática de produção de textos em português entre os juruna do Xingu. Dissertação (Mestrado). Universidade Estadual Paulista, câmpus de Araraquara.2015. 
Recursos coesivos de textos de alunos e professores da escola juruna: análise para uma contribuição ao ensino. Trabalho de Conclusão de Curso. Araraquara: UNESP, 2011.

NEVES, M. H. M. A Gramática funcional. São Paulo, Martins Fontes. 1997.

PEZATTI, E.C. Panorama geral das Teorias Funcionalistas. Signótica. Edição Especial n. 2, pp. 153-166, 2006.

PROJETO POLÍTICO PEDAGÓGICO DA ESCOLA ESTADUAL INDÍGENA DE EDUCAÇÃO BÁSICA CENTRAL KAMADU POVO YUDJA. Aldeia Tuba Tuba. Mato Grosso. 2008

SANTEE, N.R.; TEMER, A.C.R.P. A Linguística de Roman Jakobson: Contribuições para o Estudo da Comunicação. UNOPAR Científica Ciências Humanas e Educação. Londrina, v. 12, n. 1, pp. 73-82, Jun. 2011.

Disponível em: www.pgsskroton.com.br/seer/index.php/ensino/article/download/2890/2762 Acesso: 13/07/2017.

SANTOS, Z.B.F. A Linguística Sistêmico-Funcional: algumas considerações. SOLETRAS Número 28, jul.-dez 2014. Disponível em:

<www.e publicacoes.uerj.br/index.php/soletras/article/download/12994/12487>. Acesso: $18 / 07 / 2017$. 